\title{
Study of the Characteristics of Floating and Sunken Oil in Seawater Exposed to Long Term Weathering
}

\author{
Zhiyu Yan*, Bing Sun, Shili Yang, Yue Liu, Hui Liu and Qiaomin Wang \\ College of Environmental Science and Engineering, Dalian Maritime University, Dalian, 116026, P.R. China
}

\begin{abstract}
How the oil spill compositions change in the weathering process is an important topic for marine environment protection. In this study, long-term weathering simulation tests were conducted for 2 kinds of crude oils from the platforms of different blocks in Bohai Sea and 2 kinds of heavy marine fuel oils. Both floating oils and oils sunken in the seawater were analyzed. Gas chromatography (GC) results showed that light components $(<\mathrm{C} 17)$ within floating oils underwent complete weathering, while sunken oils can maintain a little (such as C16). Fluorescence spectra revealed that polycyclic aromatic hydrocarbons experienced the same degree of weathering in floating and sunken oils, and fuel oils lost their fluorescent characteristics in contrast with the crude oils. The vanadium content in fuel oils decreased significantly after weathering, but still about one order of magnitude higher than those in the crude oils. A method is proposed here for judging whether the oil sampled has sunken to the sea floor before floating up as the basis for further identification of its sources.
\end{abstract}

Key words: Floating oil, Long-term weathering, Sunken oil, Gas chromatography, Fluorescent spectroscopy.

\section{INTRODUCTION}

The rapid development of offshore exploitation and marine transportation of crude oil has created serious oil pollution issues worldwide, resulting in serious damage to ocean ecology and natural resources. In some cases, the spilled oils are easily observed quantitatively at the beginning, but after weathering they are not easily found to keep the conservation of mass. In recent years, unknown oil was found on some coasts, but no recent oil spill accident occurred at the surrounding areas. It is thought that the spilled oil sunk down after weathering and refloated up on the sea.

Various weathering and complex dynamic marine processes, which especially include evaporation, photolysis, and biodegradation, etc., significantly change the composition of spilled oil $[1,2]$. Understanding the characteristics of oils as they weather is essential in the evaluation of damage from oil pollution, specially for sunken oils. Many researchers have reported on the weathering characteristics of spilled oil $[3,4]$.

While the characteristics of oils undergone a continuous weathering in one process may be different from the one undergone discontinuous weathering in several processes, which are floating, sunken down and refloating up. Reports have considered the mechanisms which cause spilled oil to sink in ocean [5], while the weathering characteristics of sunken oils also need many researches. The oil spectrum and chromatogram highlight the unique characteristics of various kinds of complex oils and are often used in this area, which

\footnotetext{
*Address correspondence to this author at the Linghai Road, Dalian, P.R. China. Postcard: 116026; Tel: 0411-84724326; E-mail: yanzy@dl.cn
}

include gas chromatography (GC), liquid chromatography, gas chromatography- mass, fluorescence spectrometry, atomic absorption spectrometry, stable isotope ratio mass spectrometry, etc. [3, 4, 6-9].

In this study, a 340-day outdoor weathering test for two kinds of crude oils from different platforms of the Bohai Sea and two kinds of heavy marine fuels were carried out, during which the weathering characteristics of sunken oils were compared with those of floating oils employing commonly used analysis techniques, i.e. gas chromatography (GC), synchronous fluorescence spectrometry and atomic absorption spectrometry. This study will contribute to weathering theory for oil spills, particularly sunken oil, and also to the theory of oil destiny and tracing.

\section{MATERIALS AND METHODOLOGY}

Only heavy oil may sink in ocean, so Bohai crude oils and heavy fuel oils with the high density were chosen for the tests; these were identified as $\mathrm{C} 1, \mathrm{C} 2, \mathrm{~F} 1$ and F2. The kinematic viscosity of F1 and F2 was 180CST and 380CST, respectively.

The weathering tests were conducted outdoors in an open area in Dalian, Liaoning, China $\left(38^{\circ} 51^{\prime} 56.51^{\prime \prime} \mathrm{N}, 121^{\circ} 31^{\prime}\right.$ 16.56"E). Four plastic barrels (960 mm diameter, $710 \mathrm{~mm}$ high) were used as weathering tanks. The initial floating oil films on the seawater were $1.5-3 \mathrm{~mm}$ thick. The oil adhering to fine sand were deposited in the bottom of the barrels and were analyzed to obtain the condition of sunken oils. The seawater came from the Bohai Sea and the surface water was exposed to bubbling for four hours every day to simulate natural wave motion and oxygenation and exposed to natural wind and sunshine all day long. 
In field conditions, sunken oil may stay on the ocean floor for a very long time, so the simulation test started on October 17, 2011 and ended on September 26, 2012, lasting nearly one year. The oil was exposed to the local climatic conditions during all four distinct seasons, with an average annual temperature of $9^{\circ} \mathrm{C}$, and had a daily average temperature of $-4.5 \sim-8^{\circ} \mathrm{C}$ in January and $22 \sim 24^{\circ} \mathrm{C}$ in July; the annual sunshine time is about 2,500 hours and the sunshine rate is $60 \%$, all of which is similar to the offshore conditions on the Bohai Sea.

The following instruments were used for analyzing the oil samples: Shimadzu QP-2010 gas chromatograph (Shimadzu Corp., Kyoto, Japan), a Cary Eclipse molecular fluorescence spectrophotometer from (Varian Inc., Palo Alto, CA, US), and a TAS-990SUPER AF atomic absorption spectrophotometer (Beijing Purkinje General Instrument Ltd., Beijing, China) was used to analyze vanadium in the oil.

\section{RESULTS AND DISCUSSION}

\subsection{Gas Chromatography}

GC provides two kinds of information here: the distribution of the relative content of n-alkanes, and the diagnostic ratio of characteristic components' contents such as pristane, phytane, etc. The components of $\mathrm{C} 2$ could not be detected with GC, so GC was only used for the other three oils.

Fig. (1) shows the distribution of the n-alkanes' relative contents of the three kinds of oils in different states after weathering.

The original composition $(<\mathrm{C} 17)$ in the floating oils had been completely weathered away, and the dominant hydrocarbons were $\mathrm{C} 20 \sim \mathrm{C} 30$; the light components $(\mathrm{C} 16)$ in the sunken $\mathrm{C} 1$ and $\mathrm{F} 1$ after weathering still existed and the components $(<\mathrm{C} 23)$ were nearly the same as those before weathering. The components with $>\mathrm{C} 29$ in the sunken oil and the floating oil of F2 decreased significantly, showing the heavy components and the light components experienced different weathering processes; the former also experienced other degradation processes aside from evaporation during the longterm weathering.

The diagnostic ratio of some specific components obtained with GC usually remained stable during weathering and are often used for oil spill identification. The commonly used ratios include pristane/phytane $(\mathrm{Pr} / \mathrm{Ph})$, pristane/C17 $(\mathrm{Pr} / \mathrm{C} 17)$ and phytane/C18 (Ph/C18). Fig. (2) shows the results of the study.

The ratios of $\mathrm{C} 1$ and $\mathrm{F} 1$ were stable, but that of $\mathrm{F} 2$ changed drastically (Fig. 2). $\mathrm{Pr} / \mathrm{Ph}$ of the crude oil was higher than other ratios, but the fuel oils were not as high as the others in this case. The $\mathrm{Pr} / \mathrm{Ph}$ of sunken oils was slightly higher than those of the floating oils, while the $\mathrm{Pr} / \mathrm{C} 17$ was lower, without a significant difference.

\subsection{Fluorescent Spectroscopy}

Fig. (3) compares the fluorescence results of the four kinds of tested oils in three states: the initial state unweathered oils, oils both floating on the surface of seawater and sunken under the seawater weathered for nearly 1 year.

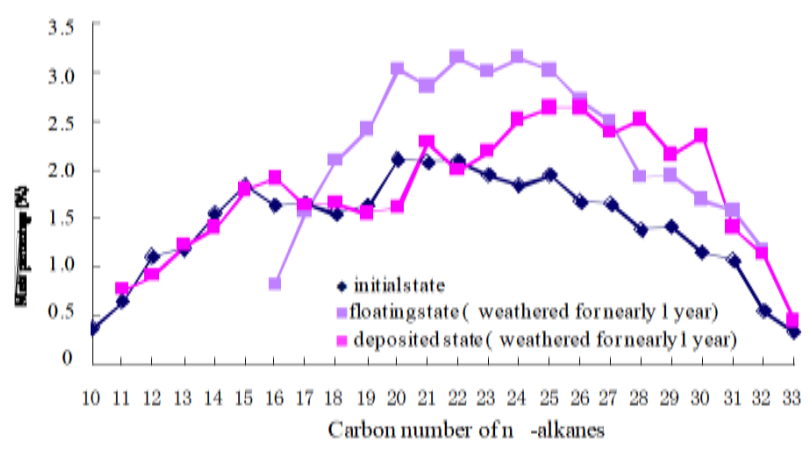

(a) $\mathrm{C}$

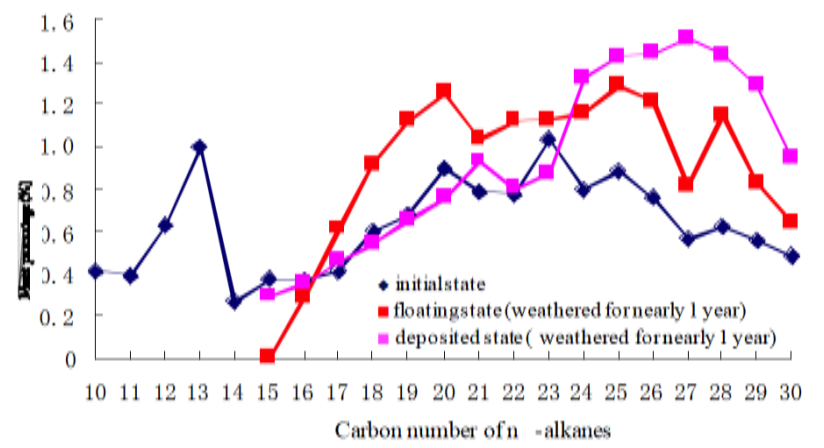

(b) F 1

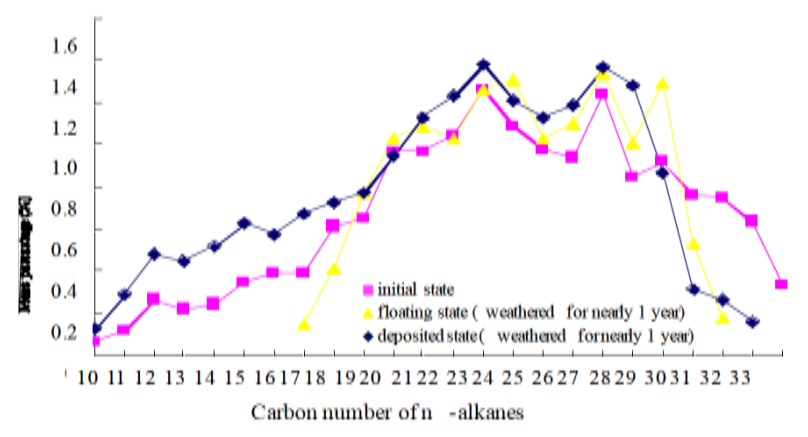

(c) F2

Fig. (1). Distribution of n-alkanes' relative contents.

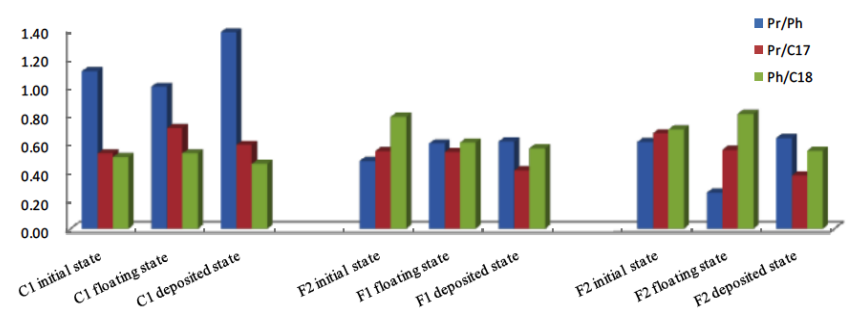

Fig. (2). pristane/phytane $(\mathrm{Pr} / \mathrm{Ph})$, pristane/C17 $(\mathrm{Pr} / \mathrm{C} 17)$ and phytane/C18 $(\mathrm{Ph} / \mathrm{C} 18)$ of oils in different states.

Before weathering, all of the oils have high peak at about $330 \mathrm{~nm}$, crude oils have a small spike at the plateau peak at about $370-380 \mathrm{~nm}$, and fuel oils have double peak initially. After weathering, the peak shapes of the two crude oils did not change greatly, although the peaks weakened significantly; but the double peaks of the two fuel oils, both floating or sunken, collapsed at $370-380 \mathrm{~nm}$. This collapse makes the crude oils and fuel oils appear very similar after weathering 
for nearly 1 year. The only difference between them might be that the crude oil still maintained a double peak, while the fuel oil maintained only a single peak at $270-300 \mathrm{~nm}$.

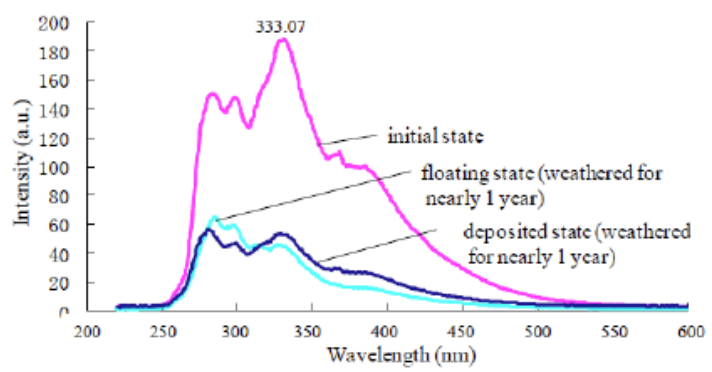

(a) $\mathrm{Cl}$

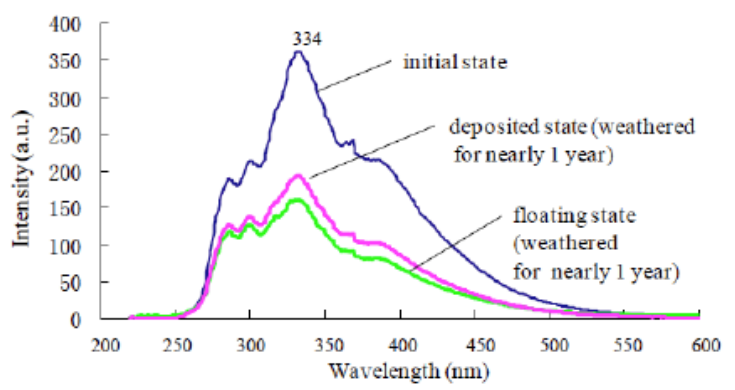

(b) $\mathrm{C} 2$

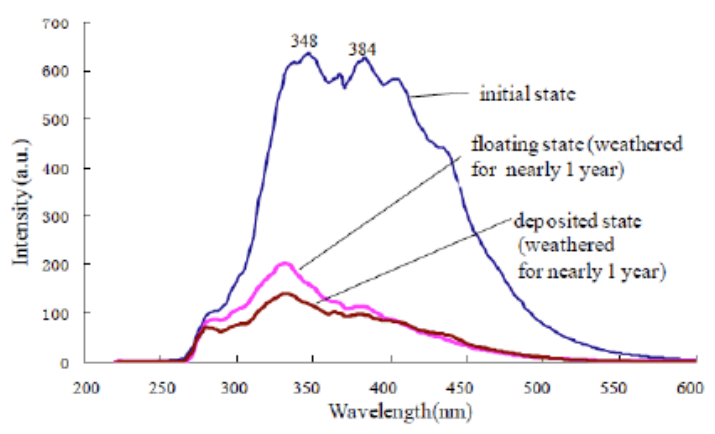

(c) F1

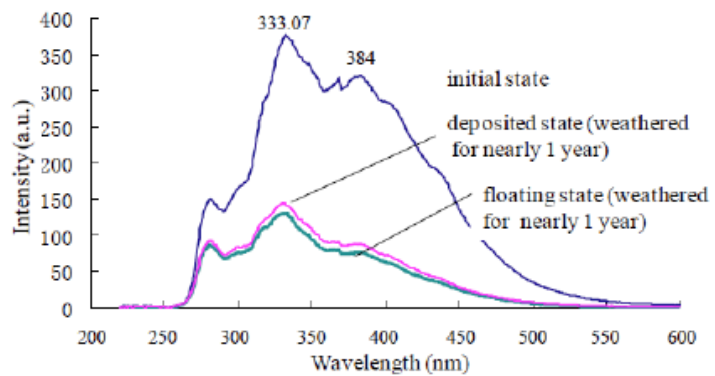

(d) F2

Fig. (3). Synchronous fluorescence spectra of oils at different states weathered for nearly 1 year.
As indicated in the spectra, the sunken oils and the floating oil did not differ greatly, except that the peak of the sunken oils was slightly higher than that of the floating oils at $>410 \mathrm{~nm}$. This may occur because they have a slightly higher content of condensed aromatics having over five cycles [10].

As shown in the above results, the characteristics of the floating oils were almost the same as those of the sunken oils after weathering for nearly 1 year. Therefore, one can conclude that the weathering of the components as shown by fluorescence was not influenced by evaporation or photolysis processes, so the same degree of weathering created similar effects over time. The weathering of such components might be correlated with fluorescent quenching caused from other processes. In addition, the fuel and crude oils were not significantly different after weathering.

\subsection{Vanadium Test Results}

Vanadium occurs in the form of organic chelates in crude oil, mostly in porphyrin chelates and perhaps in nonporphyrin chelates. Xu et al. [11] and Lou et al. [12] believe metal non-porphyrin chelates may be combined by metalloporphyrin and the asphaltene. Since porphyrin and asphaltene are highly resistant to weathering, vanadium was chosen here as the test item for measuring the long-term effects of weathering on both crude and fuel oils in the different states (Table 1).

Table 1. Vanadium content in oils $(\mathrm{mg} / \mathrm{kg})$.

\begin{tabular}{|c|c|c|c|}
\hline \multirow{2}{*}{$\begin{array}{c}\text { Sample } \\
\text { Type }\end{array}$} & \multirow{2}{*}{$\begin{array}{c}\text { Initial } \\
\text { Vanadium } \\
\text { Content }\end{array}$} & \multicolumn{2}{|c|}{$\begin{array}{c}\text { Vanadium Content in Oil Weathered } \\
\text { for Nearly 1 Year }\end{array}$} \\
\cline { 3 - 4 } & & Floating Oil & Sunken Oil \\
\hline \hline C1 & 0.542 & 1.450 & 1.188 \\
\hline C2 & 0.990 & 0.988 & 1.338 \\
\hline F1 & 163.0 & 7.9 & 3.2 \\
\hline F2 & 120.5 & 80.5 & 21.0 \\
\hline
\end{tabular}

Vanadium is mostly present in residual oils typically used as fuel; test results show that the vanadium content in fuel oils at the initial state was two orders of magnitude higher than that in the crude oils.

After weathering, except in the floating $\mathrm{C} 2$ (which basically remained unchanged), the vanadium content in both floating and sunken crude oils increased slightly, and that in fuel oils decreased substantially due to the high content of vanadium in the initial state. However, the vanadium contents in fuel oils after weathering for nearly 1 year were still over one order of magnitude higher than those in crude oils. Except for $\mathrm{C} 2$, the vanadium content in the floating oils was higher than those in the sunken oils after weathering.

Based on the above results we speculate: $\mathrm{C} 1$ is lighter than the other three oils and the light components in the floating state are substantially influenced by evaporation. As a result, the relative content of vanadium increased even as 
the components containing vanadium weathered. C2 contains fewer light components (which cannot be detected with GC under the analysis conditions used here), so the vanadium content in the floating oil basically remains unchanged, while those in the sunken oils increased relatively due to weathering of the heavy components with no vanadium.

The fuel oils showed different weathering characteristics from crude oils, i.e. the vanadium content decreased substantially after weathering, implying that the organics with vanadium are prone to substantial degradation, and this process is more likely to occur on the sea floor.

The weathering result of F2 differed greatly from that of $\mathrm{F} 1$, with the decrease in the vanadium content not being as significant as that of F1. This possibly occurred because F2 was thicker, had a higher asphalt content of containing vanadium and was more resistant to degradation.

Therefore, the heavy components can be divided into those that do not contain vanadium, those that contain vanadium and relatively readily degrade, and those contain vanadium and resist degradation. The last ones are difficult to degrade because they contain asphaltene. In any event, the weathering characteristics of the heavy components containing organic vanadium require further investigation.

\subsection{Application Recommendation}

Sometimes oil of an unknown source appears on the sea where no oil spills are known to have occurred nearby, maybe they are the sunken oil refloating on the sea. Therefore, a method is needed to speculate the weathering process when we study the oil samples. Without doubt, such method requires many research, we just propose one based on the above conclusions.

As indicated by the above, fluorescence spectra can provide details related to the process of oil weathering without the impact of the sea surface, so the point in time at which weathering of spilled oils began in the sea environment can be estimated based on the change of the spectra, no matter whether the spilled oil has sunken to the sea floor or not.

Based on the GC results, oil which has lost a higher percentage of its light components would undergo complete weathering in the floating state, while oil with some light components $(<\mathrm{C} 17)$ remaining would have sunken to the sea floor quickly after the spill occurred. Furthermore, the extent to which the vanadium content decreases can be used to judge the degree of weathering which has occurred.

The order of magnitude of the vanadium content is different between fuel oils and the crude oils. With such identifications, it is possible to ascertain whether the unknown oil is crude oil from a drilling platform, an oil tanker accident or fuel oil from ship emissions.

\section{CONCLUSION}

After weathering tests on two kinds of crude oil from different platforms in the Bohai Sea and two kinds of heavy marine fuel oils for nearly 1 year, some conclusions are obtained here as follows:
The light components $(<\mathrm{C} 17)$ in floating oil were totally lost after long-term weathering, while a little still existed in sunken oils. The fluorescence peak of sunken oils collapsed at wavelengths $>370 \mathrm{~nm}$, and the vanadium contents decreased to a greater extent on the sea floor than on the sea surface.

The fluorescent characteristics of spilled oil, which are not subject to the effect of either a floating or a sunken state, can be adopted as the basis for speculating the time at which the oil spill occurred, i.e. the start time of weathering; the loss of the light components as revealed with GC can be used as evidence to show whether bottom weathering has ever occurred to some extent, i.e. to judge whether the oil ever sank to the sea floor; and finally the extent of decrease in the vanadium content can be used to judge the extent of weathering.

The vanadium test revealed the difference of one order of magnitude in the vanadium content still existing between the fuel oils and the crude oils even after weathering for nearly 1 year.

\section{CONFLICT OF INTEREST}

The authors confirm that this article content has no conflict of interest.

\section{ACKNOWLEDGEMENTS}

This work was a part of the project "Research on the characteristics, drifting prediction and recovery technology of the Bohai submerged and sunken oil", which was funded by the Maritime Safety Administration of China. The authors wish to thank the Hebei Maritime Safety Administration of China for their help. This work was also funded by the Fundamental Research Funds for the Central Universities (No. 3132013091), National Natural Science Foundation of China (No. 41206095) and the Open Foundation of Key Laboratory of Marine Spill Oil Identification and Damage Assessment Technology (No.201110).

\section{REFERENCES}

[1] Z. Wang, and M.F. Fingas, "Development of oil hydrocarbon fingerprinting and identification techniques", Marine Pollution Bulletin, vol. 47, pp. 423-452, 2003.

[2] R.C. Prince, R.M. Garrett, and R.E. Bare, "The Roles of photooxidation and biodegradation in long-term weathering of crude and heavy fuel oils", Spill Science \& Technology Bulletin, vol. 8, pp. 145-156, 2003.

[3] L.M.V. Malmquist, R.R. Olsen, and A.B. Hansen, "Assessment of oil weathering by gas chromatography-mass spectrometry, time warping and principal component analysis", Journal of Chromatography A, vol. 1164, pp. 262-270, 2007.

[4] Y. Li, Y. Xiong, and W. Yang, "Compound-specific stable carbon isotopic composition of petroleum hydrocarbons as a tool for tracing the source of oil spills", Marine Pollution Bulletin, vol. 58, pp. 114-117, 2009.

[5] National Research Council, Spills of Nonfloating Oils: Risk and Response, Washington D.C.: National Academy Press, 1999.

[6] Z. Wang, C. Yang, and M. Fingas, "Characterization, weathering, and application of sesquiterpanes to source identification of spilled lighter petroleum products", Environ Sci Technol, vol. 39, pp. 8700-8707, 2005.

[7] J.H. Christensen, A.B. Hansen, and G. Tomasi, "Integrated methodology for forensic oil spill identification", Environ. Sci. Technol, vol. 38, pp. 2912- 2918, 2004. 
[8] N. Raquel, D. Carolina, and V. Enric, "Thermal-infrared spectral and angular characterization of crude oil and seawater emissivities for oil slick identification", Geo- science and Remote Sensing, vol. 52, pp. 5387-5395, 2014.

[9] Y. Wang, X. Liu, and Y. Sun, "Identification of oil spill from imported crude oils in china using GC/IrMS", Environmental Forensics, vol. 14, pp. 306-311, 2013.
[10] J. Xia, The utility of fluorescence analysis, Beijing: Chinese People's Public Security University press, 1992.

[11] H. Xu, D. Yu, and Z. Wang, "Petroleum porphyrin chemistry research progress", Chemical Research and Application, vol. 13, pp. 347-352, 2001

[12] S. Lou, "Existence of vanadium and nickel in crude oil and removal method", Petrochemical Corrosion and Protection, vol. 13, pp. 30-32, 1996.

Received: September 16, 2014

Revised: December 23, 2014

Accepted: December 31,2014

(C) Yan et al.; Licensee Bentham Open.

This is an open access article licensed under the terms of the Creative Commons Attribution Non-Commercial License (http://creativecommons.org/licenses/by-nc/4.0/) which permits unrestricted, non-commercial use, distribution and reproduction in any medium, provided the work is properly cited. 